\title{
南海北部神狐海域沉积物中孔隙水硫酸盐梯度 变化特征及其对天然气水合物的指示意义
}

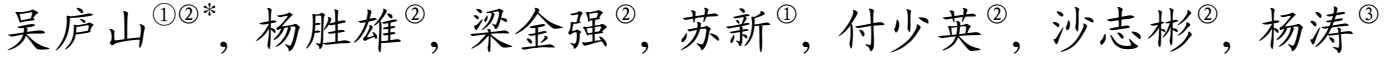 \\ (1) 中国地质大学(北京)海洋学院, 北京 100083 ; \\ (2) 广州海洋地质调查局, 广州 510760 ; \\ (3) 南京大学内生金属矿床成矿机制研究国家重点实验室, 南京大学海洋地球化学研究中心, 南京 210093 \\ *E-mail: 563wls@163.com
}

收稿日期: 2012-04-01; 接受日期: 2012-08-28

国家重点基础研究发展计划(编号: 2009CB219508, 2009CB219502)和国土资源部公益性行业科研专项(编号: 200811014)资助

\begin{abstract}
摘要南海北部陆坡神狐海域是中国天然气水合物勘探最具潜力的区域之一。对该 海域 53 个站位的孔隙水硫酸盐梯度、硫酸盐-甲烷界面(Sulfate-Methane Interface, SMI) 和硫酸盐通量等进行计算和综合分析, 结果显示孔隙水 $\mathrm{SO}_{4}{ }^{2-}$ 浓度梯度范围为 0.33 4.43 $\mathrm{mmol} \mathrm{L}^{-1} \mathrm{~m}^{-1}$, SMI 深度范围为 7.7 87.9 mbsf. 计算得出硫酸盐通量范围为 2.0 26.9 mmol m $\mathrm{m}^{-2} \mathrm{a}^{-1}$, 平均为 $11.7 \mathrm{mmol} \mathrm{m}^{-2} \mathrm{a}^{-1}$. 53 个站位的 SMI 深度与甲烷通量相关 系数为 -0.80 , 表明 SMI 深度受甲烷通量影响, 甲烷通量控制了甲烷厌氧氧化反应 (Anaerobic Methane Oxidation, AMO)的速率以及 SMI 的深度和硫酸盐通量. 似海底反 射(Bottom Simulating Reflector, BSR)基本上分布于 SMI 埋深小于 $50 \mathrm{mbsf}$ 或硫酸盐通量 大于 $3.5 \mathrm{mmol} \mathrm{m} \mathrm{m}^{-2} \mathrm{a}^{-1}$ 的区域, 钻探获得水合物实物样品的 SH2B, SH3B 和 SH7B 三个钻 孔的 BSR 埋深和 SMI 埋深的比值分别为 8.36, 8.60 和 9.94. 结合地球化学和地球物理方 法进行综合分析, 认为白云凹陷和南部隆起是神狐海域天然气水合物发育的有利区.
\end{abstract}

\section{关键词}

神狐海域 硫酸盐梯度 硫酸盐-甲烷界面(SMI) 硫酸盐通量

BSR 天然气水合物
海洋中存在大量的溶解硫酸盐 $\left(\mathrm{SO}_{4}{ }^{2-}\right)$, 它是海 洋沉积物早期成岩作用过程中孔隙水的主要化学成 份之一. 在厌氧的海洋沉积物中, 硫酸盐发生了两种 由微生物作用引起的化学反应, 其结果导致了孔隙 水中硫酸盐浓度在硫酸盐还原带发生亏损, 硫酸盐 浓度随着沉积物埋藏深度的增加而降低. 在第一种 化学反应中, 硫酸盐作为氧化剂与沉积物有机质 (Sedimentary Organic Matter, SOM)发生反应, 硫酸根
本身随着反应的进行被消耗 ${ }^{[1 \sim 3]}: 2\left(\mathrm{CH}_{2} \mathrm{O}\right)+\mathrm{SO}_{4}{ }^{2-} \rightarrow$ $2 \mathrm{HCO}_{3}{ }^{-}+\mathrm{H}_{2} \mathrm{~S}$. 第二种反应只发生在硫酸盐-甲烷界面 这个局部层位，即在硫酸盐还原带底部发生甲烷厌 氧氧化反应 $(\mathrm{AMO})$, 该反应由甲烷代替有机质作为 还原剂与硫酸盐发生反应 ${ }^{[4]}: \mathrm{CH}_{4}+\mathrm{SO}_{4}{ }^{2-} \rightarrow \mathrm{HCO}_{3}{ }^{-}+$ $\mathrm{HS}^{-}+\mathrm{H}_{2} \mathrm{O}$. 由于第二种反应比第一种反应消耗能量 更少, 所以在天然气水合物赋存区 $\mathrm{AMO}$ 占主导 ${ }^{[5 \sim 9]}$. 在硫酸盐还原带和 SMI 之下是甲烷生成带, 甲烷浓

\footnotetext{
中文引用格式: 吴庐山, 杨胜雄, 梁金强, 等. 南海北部神狐海域沉积物中孔隙水硫酸盐梯度变化特征及其对天然气水合物的指示意义. 中国科学: 地球科 学, 2013, 43: 339-350

英文引用格式: Wu L S, Yang S X, Liang J Q, et al. Variations of pore water sulfate gradients in sediments as indicator for underlying gas hydrate in Shenhu Area, the South China Sea. Science China: Earth Sciences, 2013, 56: 530-540, doi: 10.1007/s11430-012-4545-6
} 
度开始随着深度的增加而增加. 在海洋沉积物中以 微生物为介质一般可通过二氧化碳还原 $\left(\mathrm{CO}_{2}+4 \mathrm{H}_{2} \rightarrow\right.$ $\left.\mathrm{CH}_{4}+2 \mathrm{H}_{2} \mathrm{O}\right)$ 和醋酸根发酵 $\left(\mathrm{CH}_{3} \mathrm{COOH} \rightarrow \mathrm{CH}_{4}+\mathrm{CO}_{2}\right)$ 两 个独立的途径产生甲烷 ${ }^{[10]}$.

为了确定孔隙水硫酸盐梯度变化和大陆边缘天 然气水合物的关系, Borowski 等 ${ }^{[6]}$ 在全球尺度上用全 球 DSDP 和 ODP 站位孔隙水地球化学资料、在区域 尺度上用北美东南部陆缘的 Carolina Rise-Blake Ridge(CR-BR 地区) 的重力活塞取样岩心及该地区 ODP 钻孔的孔隙水地球化学资料研究了水合物赋存 与硫酸盐浓度梯度的关系. 在全球尺度上, 有天然气 水合物的陆坡站位与浅 SMI 和大的硫酸盐梯度之间 存在很强的相关性, 在这些区域 SMI 深度一般都小 于 $50 \mathrm{mbsf}$. 例如, ODP164 航次 997 钻孔的孔隙水中 $\mathrm{SO}_{4}{ }^{2-}$ 浓度大幅下降, 并在 $23 \mathrm{mbsf}$ 处降为 $0^{[11]}$; 这种 现象在 ODP204 航次 $1244 \mathrm{C}$ 钻孔 ${ }^{[12]}$ 和 IODP311 航次 U1328 钻孔 ${ }^{[13]}$ 也有表现. 在区域尺度上, CR-BR 地区 的有机质类型和质量变化都很小，因此它们对硫酸 盐梯度变化的影响程度也大致相似, 而硫酸盐和甲 烷之间通过 AMO 共同消耗是控制富含甲烷沉积物中 硫酸盐梯度变化的一个重要因素, 该地区硫酸盐梯 度和 SMI 深度变化是由于上升的甲烷通量的变化造 成的. 甲烷通量高则 SMI 浅、硫酸盐通量高, 甲烷通 量低则 SMI 深、硫酸盐通量低, 而甲烷通量的大小直 接反映了下伏沉积物中甲烷含量(可能由天然气水合 物的分解引起的)的高低 ${ }^{[5,8,14]}$. 由此反过来可以从 SMI 深度和硫酸盐通量来推测甲烷通量的大小, 进 而判断下伏沉积物中的甲烷通量和是否赋存有天然 气水合物. 此外, 最近研究发现甲烷渗漏的通量在时 间和空间上都是多变的, 它控制了沉积的氧化还原 环境 ${ }^{[15 ~ 17]}$, 而且对天然气水合物的形成和聚集也有 明显的影响 ${ }^{[18,19]}$.

南海北部神狐海域天然气水合物勘查区许多站 位的沉积物孔隙水也表现出了线性、大的硫酸盐梯度 变化和浅的 SMI 特征, 但仅有极少数学者对此进行 了报道. 如 Yang 等 ${ }^{[20,21]}$ 计算得出神狐海域两个站位 的 SMI 深度分别为 10.0 和 $11.1 \mathrm{mbsf}$ ，对应的硫酸盐 通量分别为 $26.1 \times 10^{-4}$ 和 $20.1 \times 10^{-4} \mathrm{mmol} \mathrm{cm}^{-2} \mathrm{a}^{-1}$. 吴 能友等 ${ }^{[22]}$ 和 $\mathrm{Wu}$ 等 ${ }^{[23]}$ 计算了神狐海域 6 个重力活塞 取样站位的 SMI 深度为 $10.3 \sim 22.3 \mathrm{mbsf}$, 5 个水合物钻 孔的 SMI 深度为 17.0 27.0 mbsf, 其中钻获天然气水 合物实物样品的 SH2, SH3 和 SH7 站位的 SMI 深度分
别为 26, 27 和 $17 \mathrm{mbsf}$, 这与国际上已证实的存在天 然气水合物海区的 SMI 深度小于 $50 \mathrm{mbsf}$ 的论断完全 符合. 但是他们的研究成果仅局限于某几个站位，而 对本海域硫酸盐梯度、SMI 深度和硫酸盐通量的特 征、区域分布及其影响因素，以及与 BSR 分布的关 系则没有进一步的研究. 本文以多年来神狐海域水 合物资源调查获得的 60 个重力活塞柱状沉积物样品 的孔隙水硫酸盐数据为基础, 并结合 5 个水合物钻孔 的钻探成果和区域地质资料，研究该区硫酸盐梯度、 SMI 深度和硫酸盐通量及区域分布特征，并对它们 的影响因素进行分析, 最后探讨 SMI 深度和硫酸盐 通量与 BSR 及天然气水合物之间的关系，确定天然 气水合物资源赋存的有利目标区，指导该区域天然 气水合物资源的进一步勘探.

\section{1 研究区概况}

研究区的地理位置位于南海北部陆坡中段的神 狐暗沙东南海域附近，即西沙海槽与东沙群岛之间 海域; 构造上位于珠江口盆地珠二坳陷的白云凹陷 和南部隆起、一统隆起和双峰北盆地, 其西部和南部 分别与西沙海槽盆地和双峰南盆地相接(图 1). 珠江 口新生代沉积盆地的形成和演化经历了断陷发育阶 段(古新世-早渐新世)、断坳-坳陷发育阶段(晚渐新 世-中中新世)和块断升降-披覆沉积阶段(晚中新世第四纪)三个阶段 ${ }^{[24]}$. 神狐海域从新近纪以来, 发育 了大量的深水扇沉积体 ${ }^{[25]}$, 其沉积速率相对较高, 有 机质丰富, 更新统、上新统和中新统平均沉积速率分 别为 110,38 和 $27 \mathrm{~m} \mathrm{Ma}^{-1[26]}$. 新近纪断层发育, 可分 为晚中新世活动的 $\mathrm{NW}(\mathrm{NNW})$ 向断层和上新世以来 活动的 $\mathrm{NE}(\mathrm{NNE})$ 断层两组. 其中 $\mathrm{NW}(\mathrm{NWW})$ 向断层 主要发育于晚中新世, 大部分切穿晚中新世一上新 世的各套沉积层, 并与深部断裂相连; NE 向断层活 动强度小, 规模大, 从下至上切穿上新世以来沉积层, 形成高角度断裂和垂向裂隙系统 ${ }^{[27]}$. 在神狐海域, 还 发现和识别出中央底辟带, 底辟构造包括龟背上拱、 弱刺穿、气烟图、底辟断层(或裂缝)、海底麻坑等类 型，分别代表了由塑性上拱一弱刺穿一强刺穿一塌 陷等不同演化阶段和不同幅度的底辟作用结果 ${ }^{[28]}$. 此外, 由于受等深流和海底滑塌双重作用, 在神狐海 域的坡折带或陡峭的陆坡上还大量发育与 BSR 相伴 生的海底滑塌构造 ${ }^{[29,30]}$. 由此可见，神狐海域具备良 


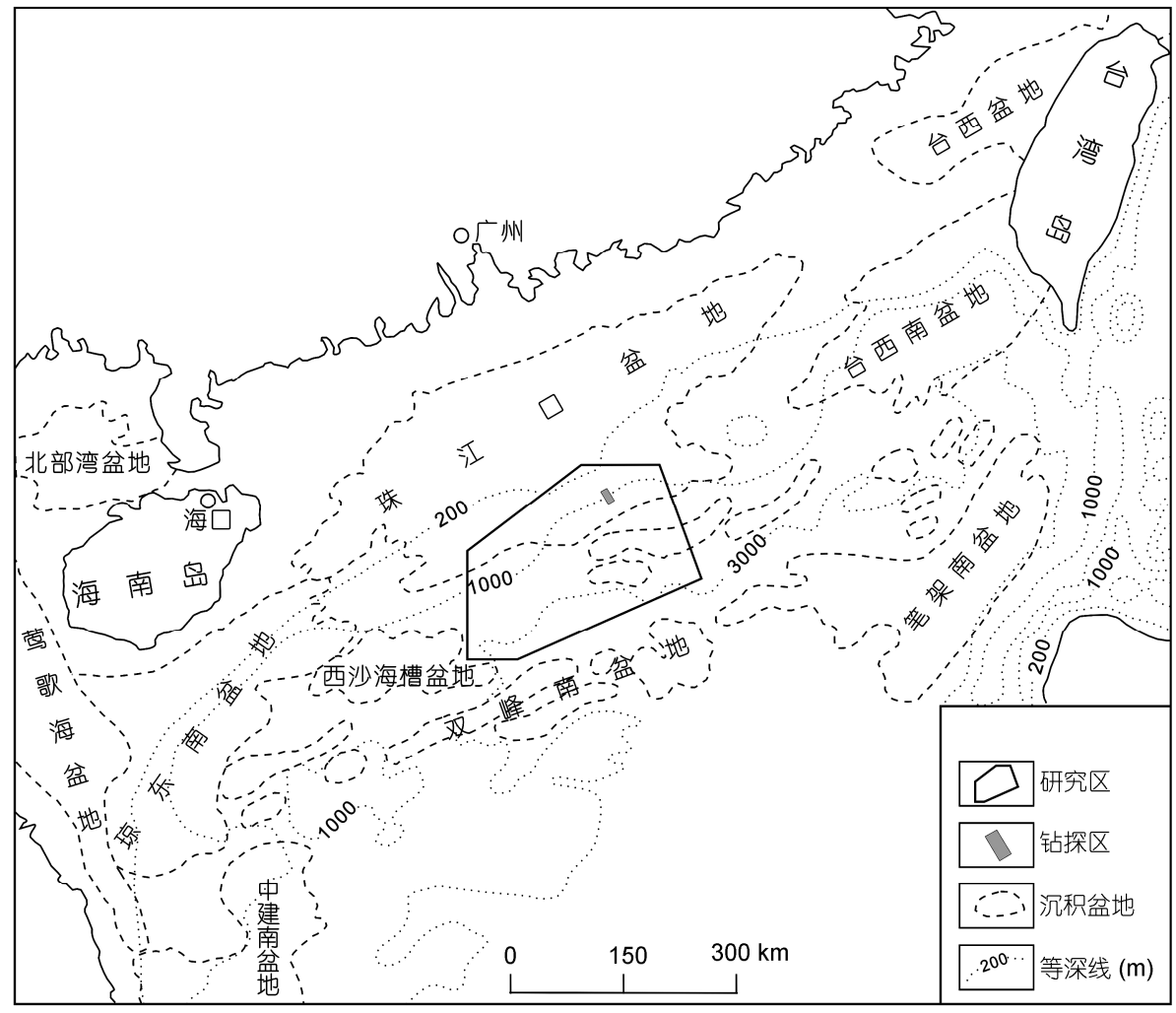

图 1 研究区位置图

好的天然气水合物成藏地质条件. 我国于 2007 年 4 6 月在该海域钻探成功获得天然气水合物实物样 品, 这进一步表明了神狐海域有着巨大的天然气水 合物资源前景 ${ }^{[31]}$.

\section{2 样品采集和分析方法}

研究样品为广州海洋地质调查局“海洋四号”船 自 2004 年以来通过大型重力活塞取样器采集而得的 柱状沉积物孔隙水样品, 共计 60 个站位, 采样深度 为 4.68 9.28 m. 沉积物样品以粘土质粉砂和粉砂质 粘土为主, 均未固结成岩.

柱状样品取到甲板后, 首先测量样品底端温度, 然后从顶到底每 $0.7 \mathrm{~m}$ 间隔依次取样, 其中上部长度 为 $0.25 \mathrm{~m}$ 的样品进行现场测试游离态烃类气体和提 取孔隙水等, 下部长度为 $0.45 \mathrm{~m}$ 的样品进行标识封 存以供室内测试分析. 孔隙水的提取采用真空抽提 法, 取得 693 份孔隙水样品, 具体操作方法见文献
[32]. 提取的孔隙水样品部分用于现场测试碱度 $\left(\mathrm{HCO}_{3}{ }^{-}\right), \mathrm{PO}_{4}{ }^{3-}$ 和 $\mathrm{NH}_{4}{ }^{+}$等浓度, 另一部分用聚四氟乙 烯瓶密封保存, 保存温度为 $4^{\circ} \mathrm{C}$.

孔隙水 $\mathrm{HCO}_{3}{ }^{-}$浓度的船上现场分析采用酸碱滴 定法, 使用仪器为瑞士 Mettler Toledo 公司的 TitraMate20 滴定仪, 相对误差为 $\pm 2.5 \%$. 保存的孔隙 水样品运回陆地后委托南京大学内生金属矿床成矿 机制研究国家重点实验室进行分析测试, 测试项目 包括阴阳离子、微量元素和稳定同位素等. 其中 $\mathrm{SO}_{4}{ }^{2-}$ 含量分析采用离子色谱法, 使用仪器为瑞士万 通公司 Metrohm790IC, 对标准海水的 $\mathrm{SO}_{4}{ }^{2-}$ 含量重复 测量表明标准偏差小于 $2 \%$; 溶解无机碳(Dissolved Inorganic Carbon, DIC)的碳同位素组成 $\left(\delta^{13} \mathrm{C}_{\mathrm{DIC}}\right)$ 采用 连续流同位素质谱仪测定方法, 仪器为德国 Finnigan 公司生产的 Delta Plus XP 同位素质谱仪和 Gas Bench II 在线制样装置, 分析精度 $<0.1 \%{ }^{[20,33]}$.

5 个水合物钻孔的孔隙水地球化学资料引自 2007 年神狐海域水合物钻探现场报告 ${ }^{1)}$.

1) Fugro International (Hong Kong) Limited. Deep-water gas hydrate investigation in Shenhu survey area, South China Sea, offshore China. Factual Field Report. 2007 
沉积物孔隙水中硫酸盐梯度和 SMI 深度根据孔 隙水 $\mathrm{SO}_{4}{ }^{2-}$ 含量的一元线性回归进行计算, 采用的方 法为最小二乘法.

沉积物孔隙水的硫酸盐通量采用菲克斯第一定 律 ${ }^{[1]}$ 来计算, 其计算公式为

$$
J=-\phi D_{\mathrm{s}} \frac{\mathrm{d} c}{\mathrm{~d} x},
$$

式中 $J$ 为硫酸盐通量 $\left(\mathrm{mmol} \mathrm{m} \mathrm{m}^{-2} \mathrm{a}^{-1}\right), \phi$ 为沉积物孔隙 度, $D_{\mathrm{s}}$ 为硫酸盐在沉积物中的扩散系数, $c$ 为硫酸盐 的浓度 $\left(\mathrm{mmol} \mathrm{L}^{-1}\right), x$ 为沉积物深度 $(\mathrm{m})$.

硫酸盐在沉积物中的扩散系数 $D_{\mathrm{s}}$ 可以根据如下 公式给出 ${ }^{[34]}$ :

$$
D_{\mathrm{s}}=\frac{D_{0}}{1+n(1-\phi)},
$$

式中 $D_{0}$ 为硫酸盐在海水中的扩散系数, 取值为 $0.55 \times 10^{-9} \mathrm{~m}^{2} \mathrm{~s}^{-1[34]}$. 由于研究区沉积物主要为粘土质 粉砂和粉砂质粘土, 因此取 $n=3^{[34]}$. 对研究区内水合 物钻探 SH5C 钻孔浅表层 $24 \mathrm{~m}$ 的沉积物孔隙度进行 了分析, 其变化范围为 $63.64 \%$ 77.05\%, 平均值为 $68.39 \%$ (表 1), 因此本文 $\phi$ 取值为 $68.39 \%$.

\section{3 结果与讨论}

\section{1 硫酸盐梯度、SMI 深度和硫酸盐通量的数值 特征}

神狐海域 65 个站位的沉积物孔隙水中 $\mathrm{SO}_{4}{ }^{2-}$ 含 量的垂向变化有 53 个站位呈线性下降趋势, 除水合 物钻探 5 个站位钻穿 SMI 之外, 其他 48 个重力活塞 取样站位的取样深度均浅于 SMI. 对这些站位的孔 隙水 $\mathrm{SO}_{4}{ }^{2-}$ 含量进行线性回归拟合, 调整的判定系数 (Adjusted R-Square)为 0.902 0.998, 说明计算得出的 硫酸盐梯度和 SMI 深度可信度较高. 表 2 为 HS-
210PC, SH7B, SH3B, HS-35PC, HS08-7PC 和 HS08$8 \mathrm{PC}$ 等 6 个代表性站位的沉积物孔隙水 $\mathrm{SO}_{4}{ }^{2-}$ 浓度测 试结果, 图 2 为这六个站位的孔隙水 $\mathrm{SO}_{4}{ }^{2-}$ 浓度的深 度剖面. 线性回归拟合得出的硫酸盐梯度分别为 $2.78,1.58,1.17,0.74,0.65$ 和 $0.38 \mathrm{mmol} \mathrm{L}^{-1} \mathrm{~m}^{-1}$, SMI 深度分别为 $8.5,17.1,22.8,36.4,43.7$ 和 $74.5 \mathrm{mbsf}$. 所 有 53 个站位计算得出的硫酸盐梯度范围为 $0.33 \sim 4.43$ $\mathrm{mmol} \mathrm{L}^{-1} \mathrm{~m}^{-1}$, SMI 深度范围为 7.7 87.9 mbsf (表 3). 其中 SMI 深度 $<20 \mathrm{mbsf}$ 的站位有 32 个, $<50 \mathrm{mbsf}$ 的 站位有 48 个, $>50 \mathrm{mbsf}$ 的站位有 5 个. 另外 12 个站 位的孔隙水 $\mathrm{SO}_{4}{ }^{2-}$ 含量深度变化无线性特征, 无法根 据线性回归方法计算硫酸盐梯度和 SMI 深度.

采用菲克斯第一定律计算得出 53 个站位的硫酸 盐通量范围为 $2.0 \sim 26.9 \mathrm{mmol} \mathrm{m}^{-2} \mathrm{a}^{-1}$, 平均为 11.7 $\mathrm{mmol} \mathrm{m}{ }^{-2} \mathrm{a}^{-1}$, 其中 $3.0 \sim 6.0$ 和 $12.0 \sim 21.0 \mathrm{mmol} \mathrm{m} \mathrm{m}^{-2} \mathrm{a}^{-1}$ 的共有 31 个站位, 而 $<3.0 \mathrm{mmol} \mathrm{m}{ }^{-2} \mathrm{a}^{-1}$ 和 $>21.0 \mathrm{mmol}$ $\mathrm{m}^{-2} \mathrm{a}^{-1}$ 的一共只有 6 个站位(表 3). 神狐海域的硫酸 盐通量与一些天然气水合物赋存区海域的值相比相

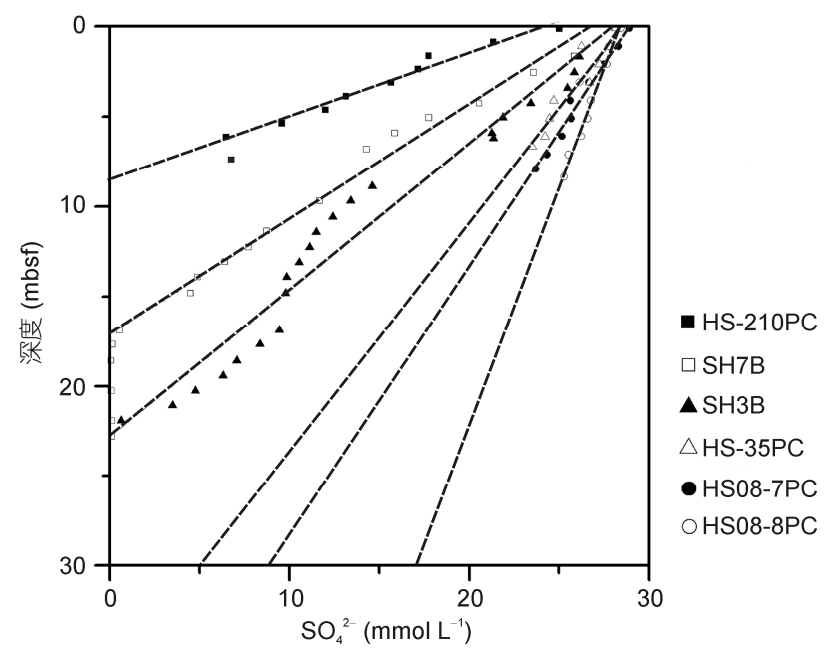

图 2 神狐海域代表性站位的沉积物孔隙水 $\mathrm{SO}_{4}{ }^{2-}$ 含量的 深度剖面

\begin{tabular}{|c|c|c|c|c|c|}
\hline 深度(mbsf) & 孔隙度 $(\%)$ & 深度(mbsf) & 孔隙度 $(\%)$ & 深度(mbsf) & 孔隙度 $(\%)$ \\
\hline 0.25 & 76.59 & 8.40 & 68.60 & 16.40 & 65.13 \\
\hline 1.25 & 77.05 & 9.45 & 66.46 & 17.45 & 67.55 \\
\hline 2.75 & 73.65 & 10.30 & 67.24 & 18.80 & 64.77 \\
\hline 3.60 & 74.14 & 11.60 & 65.23 & 19.80 & 66.67 \\
\hline 4.45 & 71.14 & 12.65 & 66.40 & 20.50 & 66.62 \\
\hline 5.40 & 71.01 & 13.60 & 65.26 & 21.70 & 65.60 \\
\hline 6.55 & 70.34 & 14.60 & 65.65 & 22.70 & 65.71 \\
\hline 7.40 & 70.36 & 15.40 & 63.64 & 23.35 & 66.43 \\
\hline
\end{tabular}

表 1 神狐海域水合物钻探 SH5C 孔沉积物的孔隙度 
表 2 神狐海域代表性站位的沉积物孔隙水 $\mathrm{SO}_{4}{ }^{2-}$ 浓度测试结果

\begin{tabular}{|c|c|c|c|c|c|c|c|c|}
\hline 站位 & $\begin{array}{c}\text { 深度 } \\
\text { (mbsf) }\end{array}$ & $\begin{array}{c}\text { 浓度 } \\
\left(\mathrm{mmol} \mathrm{L}^{-1}\right) \\
\end{array}$ & 站位 & $\begin{array}{c}\text { 深度 } \\
\text { (mbsf) }\end{array}$ & $\begin{array}{c}\text { 浓度 } \\
\left(\mathrm{mmol} \mathrm{L}^{-1}\right)\end{array}$ & 站位 & $\begin{array}{c}\text { 深度 } \\
\text { (mbsf) }\end{array}$ & $\begin{array}{c}\text { 浓度 } \\
\left(\mathrm{mmol} \mathrm{L}^{-1}\right) \\
\end{array}$ \\
\hline \multirow{10}{*}{ HS-210PC } & 0.13 & 25.00 & \multirow{22}{*}{ SH3B } & 1.66 & 26.13 & \multirow{6}{*}{ HS-35PC } & 2.10 & 27.24 \\
\hline & 0.88 & 21.34 & & 2.55 & 25.85 & & 3.10 & 26.70 \\
\hline & 1.63 & 17.74 & & 3.40 & 25.47 & & 4.10 & 24.71 \\
\hline & 2.38 & 17.14 & & 4.25 & 23.43 & & 5.10 & 24.47 \\
\hline & 3.13 & 15.64 & & 5.06 & 21.89 & & 6.10 & 24.21 \\
\hline & 3.88 & 13.14 & & 5.91 & 21.26 & & 6.66 & 23.49 \\
\hline & 4.63 & 11.99 & & 6.20 & 21.35 & & 0.10 & 28.93 \\
\hline & 5.38 & 9.58 & & 8.85 & 14.60 & & 1.10 & 28.31 \\
\hline & 6.13 & 6.46 & & 9.66 & 13.42 & & 2.10 & 27.49 \\
\hline & 7.39 & 6.76 & & 10.55 & 12.41 & & 3.10 & 26.66 \\
\hline \multirow{13}{*}{ SH7B } & 1.66 & 25.84 & & 11.40 & 11.50 & HS08-7PC & 4.10 & 25.64 \\
\hline & 2.55 & 23.57 & & 12.25 & 11.13 & & 5.10 & 25.68 \\
\hline & 4.25 & 20.55 & & 13.10 & 10.55 & & 6.10 & 25.17 \\
\hline & 5.06 & 17.75 & & 13.91 & 9.85 & & 7.10 & 24.33 \\
\hline & 5.91 & 15.86 & & 14.80 & 9.78 & & 7.90 & 23.71 \\
\hline & 6.80 & 14.28 & & 16.85 & 9.44 & \multirow{9}{*}{ HS08-8PC } & 0.10 & 28.43 \\
\hline & 9.66 & 11.67 & & 17.66 & 8.36 & & 1.10 & 27.80 \\
\hline & 11.36 & 8.72 & & 18.55 & 7.06 & & 2.10 & 27.66 \\
\hline & 12.25 & 7.73 & & 19.40 & 6.32 & & 3.10 & 26.13 \\
\hline & 13.06 & 6.43 & & 20.25 & 4.76 & & 4.10 & 26.78 \\
\hline & 13.91 & 4.88 & & 21.06 & 3.49 & & 5.10 & 26.59 \\
\hline & 14.80 & 3.30 & & 21.91 & 0.63 & & 6.10 & 26.24 \\
\hline & 16.85 & 0.92 & \multirow{2}{*}{ HS-35PC } & 0.10 & 28.15 & & 7.10 & 25.51 \\
\hline SH3B & 0.85 & 21.62 & & 1.10 & 26.25 & & 8.35 & 25.28 \\
\hline
\end{tabular}

表 3 神狐海域 53 个站位沉积物孔隙水的硫酸盐梯度、SMI 深度和硫酸盐通量计算结果 ${ }^{\text {a) }}$

\begin{tabular}{|c|c|c|c|c|c|c|c|}
\hline 站位 & $\begin{array}{c}\text { 硫酸盐梯度 } \\
\left(\mathrm{mmol} \mathrm{L} \mathrm{L}^{-1} \mathrm{~m}^{-1}\right)\end{array}$ & $\begin{array}{c}\text { SMI 深度 } \\
(\mathrm{mbsf})\end{array}$ & $\begin{array}{c}\text { 硫酸盐通量 } \\
\left(\mathrm{mmol} \mathrm{m}^{-2} \mathrm{a}^{-1}\right) \\
\end{array}$ & 站位 & $\begin{array}{c}\text { 硫酸盐梯度 } \\
\left(\mathrm{mmol} \mathrm{L}^{-1} \mathrm{~m}^{-1}\right)\end{array}$ & $\begin{array}{c}\text { SMI } \\
\text { 深度(mbsf) }\end{array}$ & $\begin{array}{c}\text { 硫酸盐通量 } \\
\left(\mathrm{mmol} \mathrm{m} \mathrm{m}^{-2} \mathrm{a}^{-1}\right)\end{array}$ \\
\hline HS-4PC & 2.29 & 10.7 & 13.9 & HS-312PC & 3.29 & 7.7 & 20.0 \\
\hline HS-9PC & 1.11 & 27.5 & 6.8 & HS-315PC & 2.43 & 12.9 & 14.8 \\
\hline HS-23PC & 2.79 & 10.5 & 17.0 & HS-328PC & 2.35 & 11.1 & 14.3 \\
\hline HS-26PC & 0.76 & 38.0 & 4.6 & HS-337PC & 2.57 & 11.2 & 15.6 \\
\hline HS-35PC & 0.74 & 36.4 & 4.5 & HS-338PC & 1.68 & 14.5 & 10.2 \\
\hline HS-57PC & 0.33 & 87.9 & 2.0 & HS-357PC & 2.23 & 12.4 & 13.6 \\
\hline HS-60PC & 1.5 & 23.0 & 9.1 & HS-359PC & 3.32 & 8.9 & 20.2 \\
\hline HS-80PC & 0.52 & 55.1 & 3.2 & HS-373PC & 3.22 & 9.1 & 19.6 \\
\hline HS-90PC & 0.61 & 50.2 & 3.7 & HS-381PC & 2.51 & 10.3 & 15.3 \\
\hline HS-148PC & 4.06 & 8.0 & 24.7 & HS-389PC & 2.48 & 11.7 & 15.1 \\
\hline HS-159PC & 1.27 & 14.6 & 7.7 & HS-396PC & 3.11 & 9.8 & 18.9 \\
\hline HS-171PC & 1.79 & 11.1 & 10.9 & HS-412PC & 3.86 & 8.9 & 23.5 \\
\hline HS-176PC & 4.43 & 9.8 & 26.9 & HS-428PC & 3.74 & 8.4 & 22.8 \\
\hline HS-210PC & 2.78 & 8.5 & 16.9 & HS-446PC & 2.64 & 11.9 & 16.1 \\
\hline HS-215PC & 1.98 & 12.0 & 12.1 & HS-PC500 & 2.05 & 15.5 & 12.5 \\
\hline HS-217PC & 3.06 & 9.8 & 18.6 & HS08-5PC & 0.58 & 49.8 & 3.5 \\
\hline HS-218PC & 2.35 & 9.3 & 14.3 & HS08-6PC & 0.62 & 48.6 & 3.8 \\
\hline HS-219PC & 2.36 & 10.6 & 14.4 & HS08-7PC & 0.65 & 43.7 & 4.0 \\
\hline HS-243PC & 1.02 & 23.1 & 6.2 & HS08-8PC & 0.38 & 74.5 & 2.3 \\
\hline HS-247PC & 1.13 & 22.5 & 6.9 & HS08-11PC & 0.63 & 45.6 & 3.8 \\
\hline HS-253PC & 0.56 & 45.0 & 3.4 & HS08-14PC & 0.66 & 44.1 & 4.0 \\
\hline HS-260PC & 0.53 & 50.7 & 3.2 & SH1B & 1.03 & 24.2 & 6.3 \\
\hline HS-282PC & 2.41 & 12.0 & 14.7 & $\mathrm{SH} 2 \mathrm{~B}$ & 0.56 & 26.2 & 3.4 \\
\hline HS-283PC & 2.84 & 10.4 & 17.3 & SH3B & 1.17 & 22.8 & 7.1 \\
\hline HS-289PC & 2.54 & 10.6 & 15.5 & SH5C & 2.51 & 22.5 & 15.3 \\
\hline HS-296PC & 2.3 & 11.0 & 14.0 & SH7B & 1.58 & 17.1 & 9.6 \\
\hline HS-297PC & 2.44 & 10.7 & 14.9 & & & & \\
\hline
\end{tabular}

a) 杨涛等 ${ }^{[14]}$ 对 HS-217PC 和 HS-328PC 站位计算得出的 SMI 深度分别为 10.0 和 $11.1 \mathrm{mbsf}$ ，对应的硫酸盐通量分别为 $26.1 \times 10^{-4}$ 和 $20.1 \times 10^{-4} \mathrm{mmol} \mathrm{cm}^{-2} \mathrm{a}^{-1}$ 
对偏低. 如墨西哥湾 Atwater Valley 沉积物的硫酸盐 通量为 20.4 249.1 mmol m${ }^{-2} \mathrm{a}^{-1[35]}$, 乌拉圭陆缘深海 (水深为 $5480 \mathrm{~m}$ ) 沉积物的硫酸盐通量为 $6.3 \sim 162$ $\mathrm{mmol} \mathrm{m}^{-2} \mathrm{a}^{-1[36]}$, 非洲西部陆缘 1312 2060 $\mathrm{m}$ 深水区 沉积物的硫酸盐通量为 $21.5 \sim 61.5 \mathrm{mmol} \mathrm{m}^{-2} \mathrm{a}^{-1[37]}$, 智利中部和南部陆缘的沉积物的硫酸盐通量为 22.9 362.0 $\mathrm{mmol} \mathrm{m}^{-2} \mathrm{a}^{-1[38,39]}$. 其平均值略高于布莱 克海台 ODP 164 航次取到天然气水合物实物样品的 994, 995 和 997 站位的硫酸盐通量, 后者分别为 8.6, 8.3 和 $7.9 \mathrm{mmol} \mathrm{m}^{-2} \mathrm{a}^{-1[8]}$, 但低于布莱克海台重力活 塞取样站位 PC 11-8 的 $18 \mathrm{mmol} \mathrm{m}^{-2} \mathrm{a}^{-1}$. . 也比东沙 海域 2004 年中德合作 SO-177 航次 GC-9, GC-10 和 GC-11站位的低, 后者硫酸盐通量分别为 39,38 和 59 $\mathrm{mmol} \mathrm{m} \mathrm{m}^{-2} \mathrm{a}^{-1[40]}$. 比杨涛等 ${ }^{[14]}$ 对相同站位的计算值低 (表 3). 引起这种差异的原因主要有如下两点: 一是 采用的计算公式不同, 后者的公式中没有涉及海底 浅表层沉积物类型; 二是孔隙度取值有所差别, 本文 采用的是本区水合物钻孔 SH5C 沉积物的实测孔隙 度平均值 $(68.39 \%)$, 而后者采用的是研究区以东的
ODP 184 航次 1144 站位浅层 $(0 \sim 100 \mathrm{mbsf})$ 沉积物孔隙 度的平均值 $(75 \%)^{[41]}$. 本文计算公式中若孔隙度取值 为 $75 \%$, 海底浅表层沉积物类型为砂质 $(n=2)^{[34]}$, 计 算得出这两个站位的硫酸盐通量分别为 26.5 和 20.4 $\mathrm{mmol} \mathrm{m} \mathrm{m}^{-2} \mathrm{a}^{-1}$, 与杨涛等 ${ }^{[14]}$ 的大致相当. 由此可见, 本文的硫酸盐通量计算方法既考虑到海底浅表层沉 积物类型的差别, 又采用了研究区实测的孔隙度, 计 算结果的可信度相对要高些.

\subsection{SMI 深度和硫酸盐通量的区域分布特征}

研究区的 SMI 深度具有从东北向西南变深的变 化趋势, 这种变化趋势与水深关系密切, 即随着水深 的增加而变深，一般 SMI 深度小于 $30 \mathrm{mbsf}$ 的区域的 水深浅于 $2000 \mathrm{~m}, \mathrm{SMI}$ 深度小于 $50 \mathrm{mbsf}$ 的区域的水 深浅于 $3500 \mathrm{~m}$ (图 3). 硫酸盐通量则相反, 呈由东北 向西南降低的变化趋势, 与水深的关系也比较密切, 一般硫酸盐通量大于 $6 \mathrm{mmol} \mathrm{m}^{-2} \mathrm{a}^{-1}$ 的区域的水深浅 于 $2000 \mathrm{~m}$, 硫酸盐通量大于 $3.5 \mathrm{mmol} \mathrm{m}^{-2} \mathrm{a}^{-1}$ 的区域 的水深浅于 $3500 \mathrm{~m}$ (图 4).

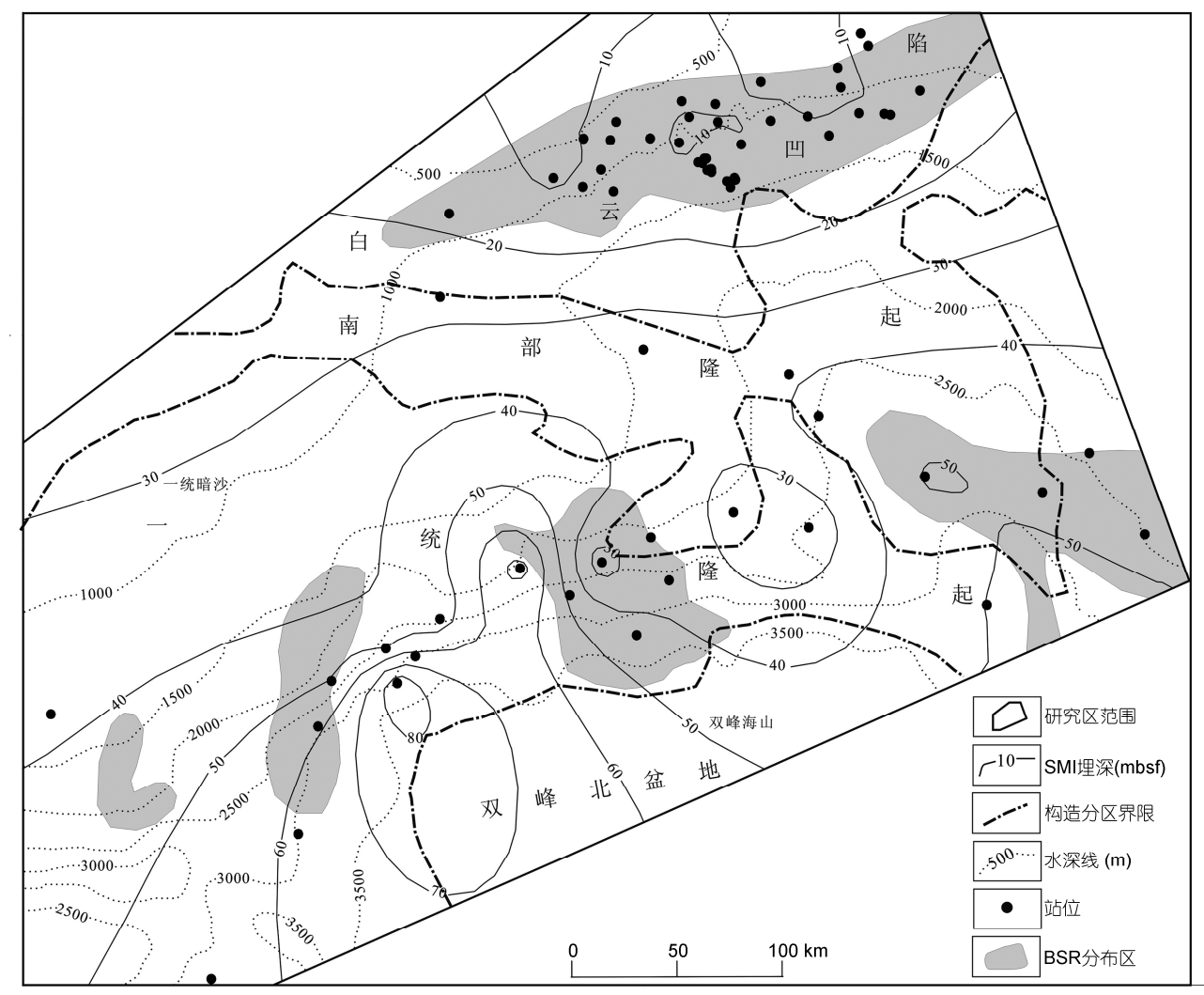

图 3 神狐海域 SMI 深度等值线与 BSR 分布图 


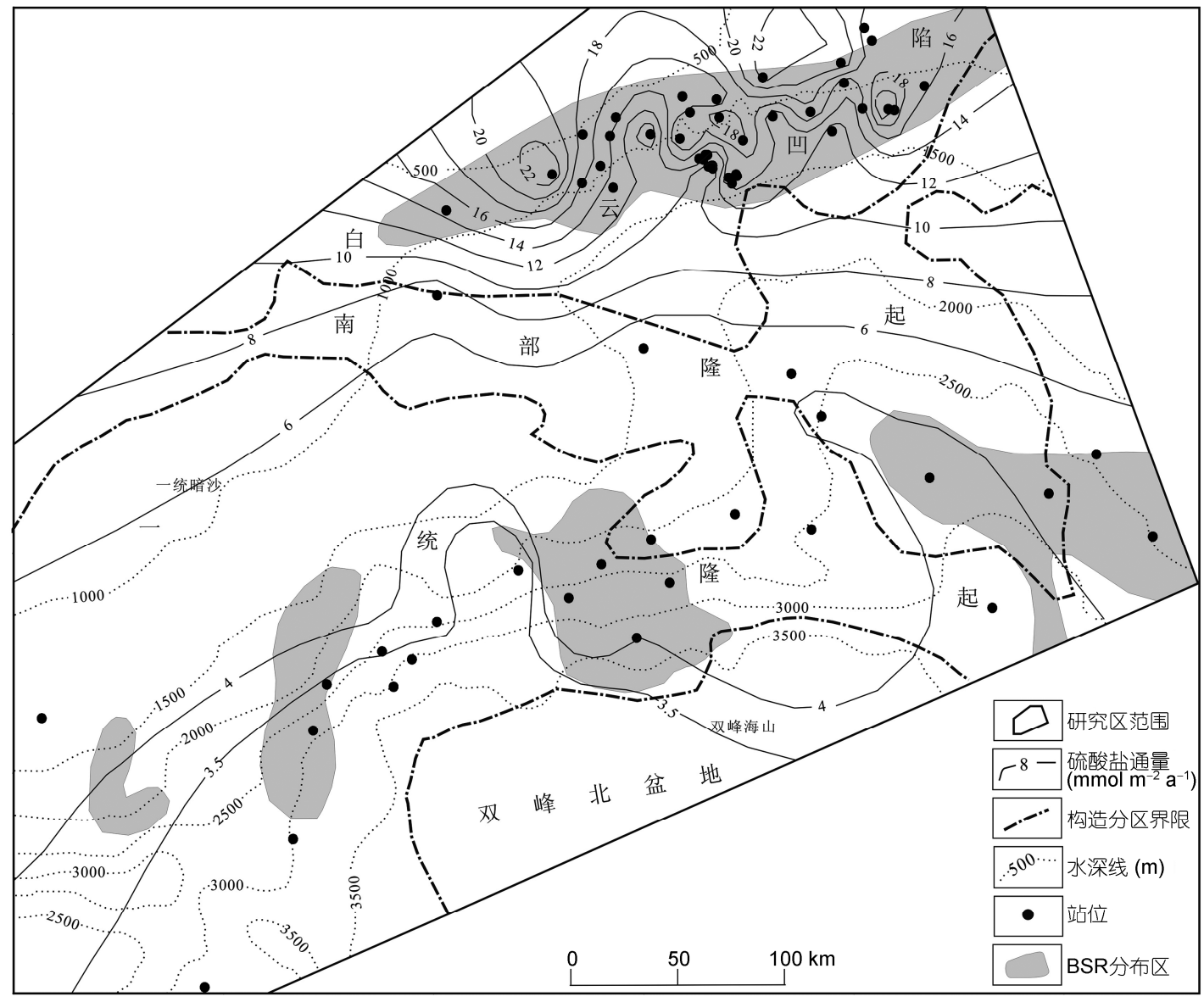

图 4 神狐海域沉积物硫酸盐通量等值线与 BSR 分布图

研究区的大地构造位置位于珠江口盆地珠二坳 陷的白云凹陷和南部隆起、一统隆起和双峰北盆地 ${ }^{29]}$. 从图 3 可以看出, 不同构造单元的 SMI 深度不同, 白 云凹陷的 SMI 深度绝大多数小于 $30 \mathrm{mbsf}$, 南部隆起 的 SMI 深度主要在 30 50 mbsf, 一统隆起的 SMI 深 度主要在 30 80 mbsf, 而双峰北盆地的 SMI 深度一 般都大于 $40 \mathrm{mbsf}$. 同样, 从图 4 可以看出, 不同构造 单元的硫酸盐通量也是不同的, 白云凹陷的硫酸盐 通量通常都大于 $10 \mathrm{mmol} \mathrm{m}^{-2} \mathrm{a}^{-1}$, 南部隆起的硫酸盐 通量主要在 $4 \sim 10 \mathrm{mmol} \mathrm{m}^{-2} \mathrm{a}^{-1}$, 一统隆起的硫酸盐通 量主要在 3.5 6 $\mathrm{mmol} \mathrm{m}^{-2} \mathrm{a}^{-1}$, 而双峰北盆地的硫酸 盐通量往往小于 $4 \mathrm{mmol} \mathrm{m}^{-2} \mathrm{a}^{-1}$.

\section{3 沉积物有机质对 SMI 深度和硫酸盐通量的影 响}

沉积物中有机质的质量和数量对孔隙水中硫酸 盐的亏损具有一定的影响作用, 而有机质由沉积作
用提供, 它与沉积速率密切相关 ${ }^{[42]}$. 神狐海域水合物 钻探成果显示: SH1B 岩心的平均沉积速率为 $31.4 \mathrm{~m}$ $\mathrm{Ma}^{-1}$, 底界年龄约为 8.3 9.6 Ma, 相当于中新世晚期; SH5C 岩心的平均沉积速率为 $39.2 \mathrm{~m} \mathrm{Ma}^{-1}$, 底界年 龄约为 $4.5 \mathrm{Ma}$, 相当于上新世早期; SH7B 岩心的平 均沉积速率为 $26.0 \mathrm{~m} \mathrm{Ma}^{-1}$, 底界年龄为 7.0 7.5 Ma, 相当于中新世晚期. 神狐海域 4 个重力活塞取样站位 的中更新世晚期的沉积速率为 179 196 $\mathrm{m} \mathrm{Ma}^{-1}$, 全 新世的沉积速率为 96 146 m Ma ${ }^{-1}$ [29]. 由此可见, 神 狐海域的沉积速率变化不大, 一般相差不到两倍. 此 外，通过对神狐海域 22 个站位的有机碳平均含量进 行统计分析，其范围为 $0.89 \%$ 1.58\%，平均值为 $1.23 \%$, 且只有 2 个站位的有机碳平均含量 $<1 \%$, 这 与世界上主要发现天然气水合物海域的浅表层沉积 物的有机碳含量较高 $(\geqslant 1 \%)$ 是相符的 ${ }^{[43]}$. 然而, 有机 碳含量的变化幅度不到 2 倍, 而 SMI 深度和硫酸盐通 量的变化幅度则高达 5 7 倍. 进一步对其中 19 个硫 
酸盐含量呈线性下降的站位的沉积物有机碳含量分 别与 SMI 深度和硫酸盐通量进行相关分析, 有机碳 含量与 SMI 深度为负中度相关, 相关系数为 -0.50 ; 有机碳含量与硫酸盐通量为正中度相关, 相关系数 为 0.57 (图 5). 因此, 神狐海域浅表层沉积物的有机 碳含量对 SMI 深度和硫酸盐通量具有一定的影响, 但不是主要控制因素.

\section{4 甲烷厌氧氧化反应对 SMI 深度和硫酸盐通量 的影响}

在甲烷富集的区域(如天然气水合物赋存区)，由 于 AMO 过程占据主要地位, 向下的硫酸盐流体与高 浓度甲烷向上扩散基本保持平衡, 并在硫酸盐还原 区保持低的还原率. 此外, 最新的研究表明相对较高 的甲烷上涌速率对应较低的硫酸盐还原速度, 而较 低的甲烷上涌速率对应较高的硫酸盐还原速度 ${ }^{[4]}$.

在这种条件下, 由于发生于 SMI 附近的 AMO 消耗了硫酸盐与甲烷, 使得硫酸盐和甲烷结成了一 对地球化学组合 ${ }^{[5]}$, 从而使沉积物孔隙水 $\mathrm{SO}_{4}{ }^{2-}$ 浓度、 碱度(alkalinity)、 $\delta^{13} \mathrm{C}_{\mathrm{DIC}}$ 和顶空气甲烷含量等在垂向 上发生一系列变化, 主要表现为: (1) $\mathrm{SO}_{4}{ }^{2-}$ 含量随深 度呈线性下降, 并在 SMI 处下降到接近 0; (2) 碱度在 SMI 之上呈升高趋势, 并在 SMI 附近达到最大值, 而 在 $\mathrm{SMI}$ 之下转呈降低趋势; (3) $\delta^{13} \mathrm{C}_{\mathrm{DIC}}$ 在 $\mathrm{SMI}$ 之上呈 降低趋势, 并在 SMI 附近达到最小值, 通常 $<-30 \%$, 这表现溶解无机碳来源于下伏沉积物中的生物成因

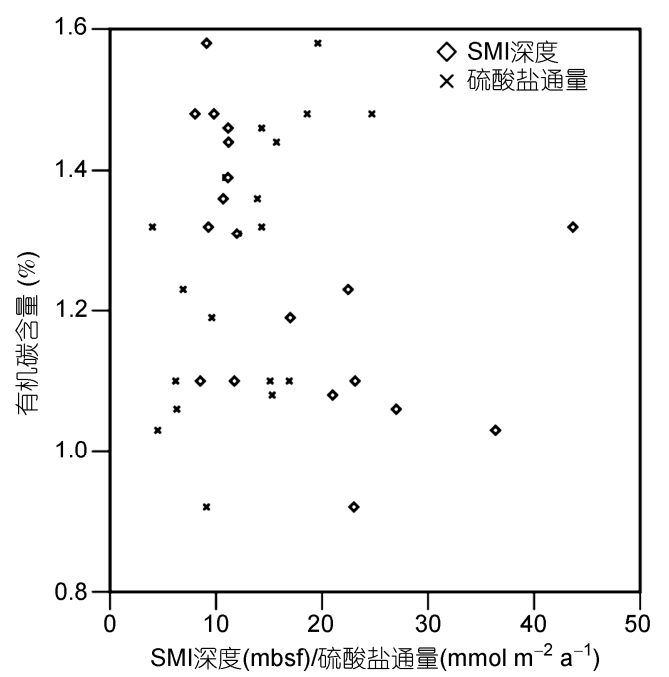

图 5 神狐海域 19 个站位的沉积物有机碳含量与 SMI 深度 和硫酸盐通量的重叠散点图
甲烷，而在 SMI 之下转呈升高趋势; (4) 顶空气甲烷 含量在 SMI 之上数值很小且变化不明显, 而在 SMI 处发生骤增 ${ }^{[7,35]}$. 神狐海域水合物钻探 SH7B 钻孔也 具有类似的特征，在 SMI(线性回归拟合深度为 17.1 mbsf) 附近也发生了强烈的甲烷厌氧氧化反应, 主要 表现为: (1) $\mathrm{SO}_{4}{ }^{2-}$ 含量随深度呈线性下降, 从 1.66 $\mathrm{mbsf}$ 的 $25.8 \mathrm{mmol} \mathrm{L}^{-1}$ 至 $17.66 \mathrm{mbsf}$ 下降到 $0.14 \mathrm{mmol}$ $\mathrm{L}^{-1}$, 之下则基本稳定. (2) 碱度在 SMI 之上呈升高趋 势, 除在最上层位 $1.80 \mathrm{mbsf}$ 为 $11.86 \mathrm{mmol} \mathrm{L}^{-1}$ 稍高外, 其他 4 个层位的几乎为线性升高, 并在 SMI 附近 $17.78 \mathrm{mbsf}$ 处达到最大值, 为 $24.26 \mathrm{mmol} \mathrm{L}^{-1}$, 而碱度 在 SMI 之下转呈降低趋势. (3) $\delta^{13} \mathrm{C}_{\mathrm{DIC}}$ 在 $\mathrm{SMI}$ 之上呈 降低趋势, 并在 SMI 附近 $17.78 \mathrm{mbsf}$ 处达到最小值, 为 $-42.29 \%$ 。 该值比布莱克海台 ODP164 航次 994 和 995 站位 $\left(\delta^{13} \mathrm{C}_{\mathrm{DIC}} \text { 分别为 }-37.3 \% \text { 。和 }-37.7 \% 0\right)^{[7]}$ 和东地 中海 Kazan 泥火山 $\left(\delta^{13} \mathrm{C}_{\mathrm{DIC}} \text { 最小值为 }-40 \% \text { o }\right)^{[45]}$ 要低,

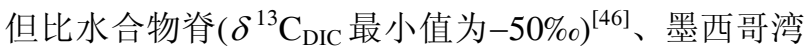
Atwater Valley 和 Keathley Canyon $\left(\delta^{13} \mathrm{C}_{\text {DIC }}\right.$ 最小值分 别为 $-46.3 \%$ 和 $-49.6 \%$ o ${ }^{[47]}$ 和挪威中部陆缘麻坑 $\mathrm{G} 11\left(\delta^{13} \mathrm{C}_{\mathrm{DIC}} \text { 最小值为 }-54.6 \% 0\right)^{[48]}$ 的要高. $\delta^{13} \mathrm{C}_{\mathrm{DIC}}$ 在 $17.78 \mathrm{mbsf}$ 之下转呈升高趋势. (4) 顶空气甲烷含量 在 $16.83 \mathrm{mbsf}$ 之上低于检测限, 之后从 $16.83 \mathrm{mbsf}$ 的 $0.09 \mathrm{mmol} \mathrm{L}^{-1}$ 线性骤增到 $21.93 \mathrm{mbsf}$ 的 $2.59 \mathrm{mmol}$ $\mathrm{L}^{-1}$, 增加了约 28 倍(表 4, 图 6).

由于被甲烷厌氧氧化作用消耗的硫酸盐和甲烷 的化学计量比为 $1: 1$, 所以两者的通量在 SMI 处大致 是相等的. 因此, 在 AMO 发生的区域硫酸盐的通量 大小与上涌的甲烷通量成正比, 可以用硫酸盐的通 量来近似地表示甲烷的通量 ${ }^{[5,35]}$. 图 2 中 6 个站位 HS210PC, SH7B, SH3B, HS-35PC, HS08-7PC 和 HS08$8 \mathrm{PC}$ 的硫酸盐(或甲烷)通量分别为 $16.9,9.6,7.1,4.5$, 4.0 和 $2.3 \mathrm{mmol} \mathrm{m}^{-2} \mathrm{a}^{-1}$, 对应的 SMI 深度分别为 8.5 , $17.1,22.8,36.4,43.7$ 和 $74.5 \mathrm{mbsf}$, 硫酸盐梯度分别为 $2.78,1.58,1.17,0.74,0.65$ 和 $0.38 \mathrm{mmol} \mathrm{L}^{-1} \mathrm{~m}^{-1}$, 可以 看出, 甲烷通量大则 SMI 深度浅和硫酸盐梯度大. 此 外, 通过对神狐海域 53 个站位的 SMI 深度与硫酸盐 (或甲烷)通量进行相关分析可知, 它们呈负高度相关, 相关系数为 -0.80 (图 7). 这表明 SMI 深度是由上涌的 甲烷通量决定的，甲烷通量的大小控制了 AMO 的速 率以及 SMI 的深浅和硫酸盐通量. 因此, 在神狐海 域, 由于下伏沉积物中甲烷含量高, 致使上涌的甲烷 通量也高, 在浅层沉积物中发生了强烈的甲烷厌氧 
表 4 神狐海域 SH7B 钻孔沉积物孔隙水的 $\mathrm{SO}_{4}{ }^{2-}$ 浓度、碱度、 $\delta^{13} \mathrm{C}_{\text {DIC }}$ 和顶空气甲烷含量的测试结果

\begin{tabular}{|c|c|c|c|c|c|c|c|}
\hline \multicolumn{2}{|c|}{ 硫酸根 } & \multicolumn{2}{|c|}{ 顶空气甲烷 } & \multicolumn{2}{|c|}{$\begin{array}{l}\text { 碱度 } \\
\end{array}$} & \multicolumn{2}{|c|}{$\delta^{13} \mathrm{C}_{\mathrm{DIC}}$} \\
\hline 深度(mbsf) & 浓度 $\left(\mathrm{mmol} \mathrm{L}^{-1}\right)$ & 深度(mbsf) & 浓度 $\left(\mathrm{mmol} \mathrm{L}^{-1}\right)$ & 深度(mbsf) & 浓度 $\left(\mathrm{mmol} \mathrm{L}^{-1}\right)$ & 深度(mbsf) & 同位素值(\%o) \\
\hline 1.66 & 25.84 & 0.83 & 0.00 & 1.80 & 11.86 & 1.80 & -16.66 \\
\hline 2.55 & 23.57 & 2.53 & 0.00 & 6.03 & 5.93 & 6.03 & -12.98 \\
\hline 4.25 & 20.55 & 4.23 & 0.00 & 9.78 & 10.78 & 9.78 & -27.91 \\
\hline 5.06 & 17.75 & 5.93 & 0.00 & 14.03 & 15.63 & 14.03 & -24.02 \\
\hline 5.91 & 15.86 & 6.78 & 0.00 & 17.78 & 24.26 & 17.78 & -42.29 \\
\hline 6.80 & 14.28 & 7.63 & 0.00 & 22.03 & 17.25 & 22.03 & -36.57 \\
\hline 9.66 & 11.67 & 8.83 & 0.00 & & & & \\
\hline 11.36 & 8.72 & 10.53 & 0.00 & & & & \\
\hline 12.25 & 7.73 & 12.23 & 0.00 & & & & \\
\hline 13.06 & 6.43 & 13.93 & 0.00 & & & & \\
\hline 13.91 & 4.88 & 15.63 & 0.03 & & & & \\
\hline 14.80 & 3.30 & 16.83 & 0.09 & & & & \\
\hline 16.85 & 0.92 & 18.53 & 0.87 & & & & \\
\hline 17.66 & 0.14 & 20.23 & 1.84 & & & & \\
\hline 18.55 & 0.06 & 21.93 & 2.59 & & & & \\
\hline 20.25 & 0.08 & & & & & & \\
\hline 21.91 & 0.11 & & & & & & \\
\hline 22.80 & 0.10 & & & & & & \\
\hline
\end{tabular}

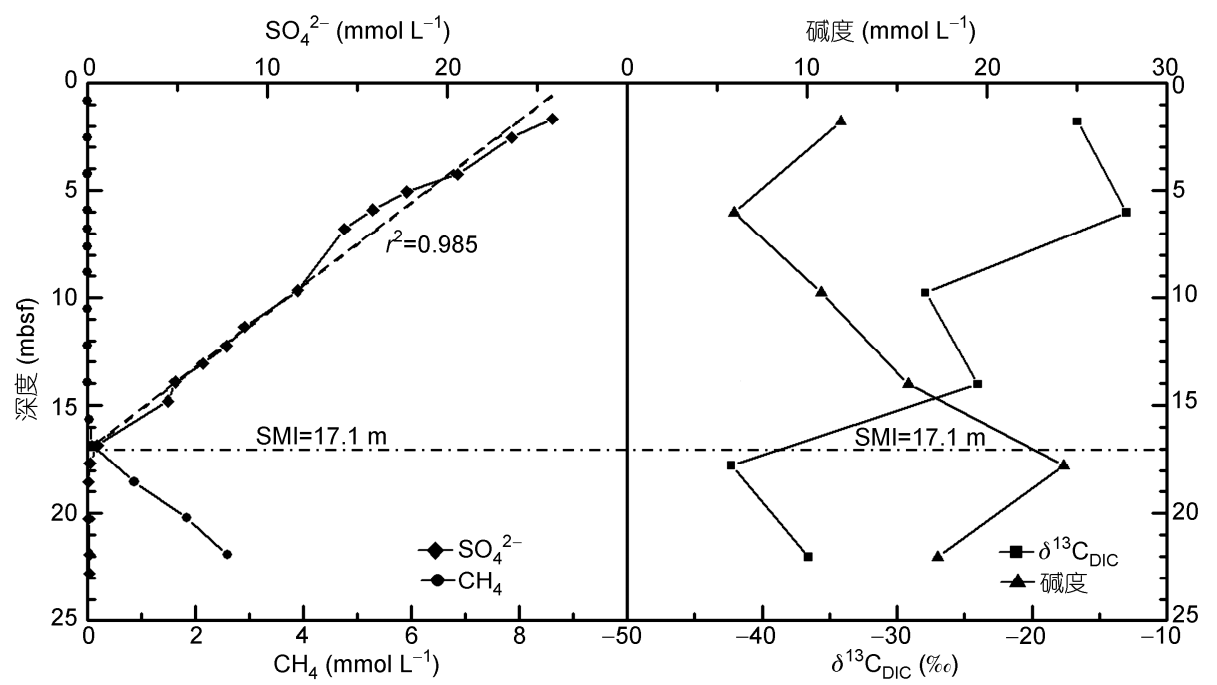

图 6 神狐海域 SH7B 钻孔沉积物孔隙水的 $\mathrm{SO}_{4}{ }^{2-}$ 浓度、碱度、 $\delta^{13} \mathrm{C}_{\mathrm{DIC}}$ 和顶空气甲烷含量的垂向变化

氧化反应，该反应消耗掉大量的硫酸盐和甲烷，从而 使 SMI 深度变浅和硫酸盐浓度梯度变大及硫酸盐通 量增大. 此外, 高通量的甲烷上涌会使浅表层沉积物 顶空气甲烷含量产生高异常, 研究区内共圈出 12 个 高异常区, 这些异常区位于南部隆起带及其与白云 凹陷的边界地段 ${ }^{[49]}$, 这是这些区域 SMI 深度较浅和 硫酸盐通量较高的主要原因.

\subsection{SMI 深度和硫酸盐通量与天然气水合物的关} 系

海底水合物探测主要是通过地球物理和地球化 学等方法进行的, 其中地球物理勘查的主要方法是 识别出代表天然气水合物稳定带底界(Base of Gas Hydrate Stability, BGHS)的 BSR ${ }^{[50 \sim 53]}$. 我国南海海域 的天然气水合物研究也是从地震剖面上识别出 BSR 


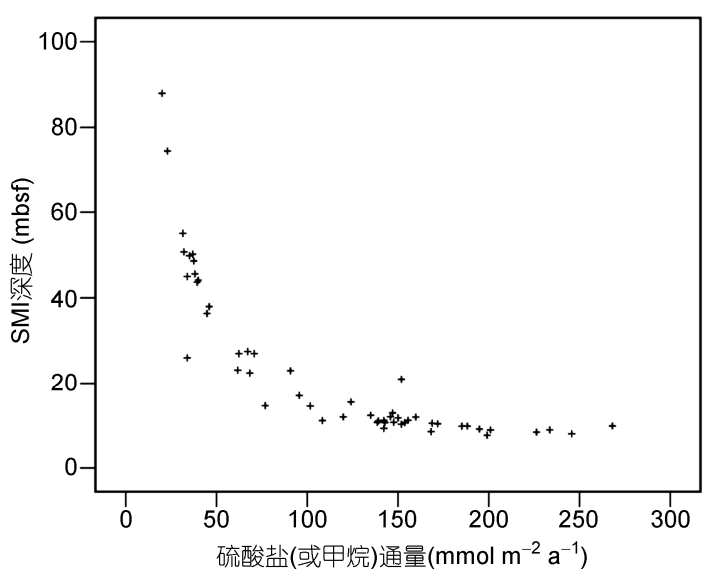

图 7 神狐海域 53 个站位的 SMI 深度和硫酸盐/甲烷扩散 通量的散点图

开始的. Reed 等 ${ }^{[54]}$ 最早报道了在南海存在 BSR, 并在 台湾南部海域鉴别出 BSR. 姚伯初 ${ }^{[55]}$ 在研究了南海 北部陆坡 10 万余公里的多道地震剖面后发现，在局 部区域发育有 BSR, 并推测这些地区存在天然气水 合物. 近几年来, 已有一些学者对神狐海域的 BSR 进行了研究工作 ${ }^{[22,27,29,30,56]}$, 但他们都没有把 BSR 与 SMI 深度和硫酸盐通量结合起来进行讨论.

本文把 SMI 深度和硫酸盐通量的等值线与 BSR 分布区进行拼叠, 以求探讨前两者与后者的关系. 从 图 3 和 4 可知: BSR 主要分布在水深 $3500 \mathrm{~m}$ 以浅的 地区, 与水深关系不大, 呈补丁状分布; BSR 基本上 分布于 $\mathrm{SMI}$ 深度 $<50 \mathrm{mbsf}$ 或硫酸盐通量 $>3.5 \mathrm{mmol}$ $\mathrm{m}^{-2} \mathrm{a}^{-1}$ 的地区. SH2B, SH3B 和 SH7B 这 3 个钻孔均位 于 BSR 分布区, SMI 深度分别为 26.2, 22.8 和 17.1 mbsf, 硫酸盐通量分别为 $3.4,7.1$ 和 $9.6 \mathrm{mmol} \mathrm{m}^{-2} \mathrm{a}^{-1}$. 因此, 结合地球化学和地球物理方法进行综合分析 可以推测: 在神狐海域, 位于 BSR 分布区, 且 SMI 深度 $<50 \mathrm{mbsf}$ 和硫酸盐(或甲烷)通量 $>3.5 \mathrm{mmol} \mathrm{m}^{-2}$ $\mathrm{a}^{-1}$ 的地区的下伏沉积物中可能赋存有天然气水合物, 这些区域主要位于白云凹陷和南部隆起带.

为了进一步探讨神狐海域 SMI 深度与水合物的 关系, 我们对 SH2B, SH3B 和 SH7B 这 3 个钻孔的 SMI, BSR 和 BGHS 相互之间进行了对比分析. 这 3 个站位的 BSR 埋深分别为 219,196 和 $170 \mathrm{mbsf}$, BGHS 埋深分别为 229, 206 和 $185 \mathrm{mbsf}$, 天然气水合 物层位于 BGHS之上 10 25 m 的沉积层中, 因此可以
近似地用 BSR 代表天然气水合物层的底界. 这 3 个 钻孔不仅反映出 SMI 埋深浅 BSR 埋深也浅的特征, 而且用这三个钻孔的 BSR 埋深与 SMI 深度进行对比, 前者分别是后者的 $8.36,8.60$ 和 9.94 倍, 它们的倍数 相差不大, 这表明 BSR 埋深与 SMI 深度之间可能存 在着密切的关系. 神狐海域 BSR 埋深与 SMI 深度的 比值要比布莱克海台和水合物脊的 19 20 倍 ${ }^{[57,58]}$ 小 得多, 至于为何会引起如此大的差异尚需结合三个 地区的区域地质资料开展进一步的研究工作.

\section{4 结论}

本文首次运用了神狐海域 53 个站位沉积物孔隙 水的地球化学调查资料, 分析了沉积物孔隙水硫酸 盐梯度、SMI 深度和硫酸盐通量的数值特征和区域分 布特征, 探讨了 SMI 深度和硫酸盐通量的影响因素 及其与 BSR 埋深、下伏水合物之间的关系, 主要认 识如下:

沉积物孔隙水硫酸盐梯度范围为 $0.33 \sim 4.43$ $\mathrm{mmol} \mathrm{L}^{-1} \mathrm{~m}^{-1}$, SMI 深度范围为 7.7 87.9 mbsf; 硫酸盐 通量范围为 $2.0 \sim 26.9 \mathrm{mmol} \mathrm{m}^{-2} \mathrm{a}^{-1}$, 平均为 $11.7 \mathrm{mmol}$ $\mathrm{m}^{-2} \mathrm{a}^{-1}$, 该值低于墨西哥湾 Atwater Valley、乌拉圭陆 缘深海、非洲西部陆缘、智利中部和南部陆缘、南海 北部东沙海域等水合物分布区，与布莱克海台的的 大致相当; 有机碳含量与 SMI 深度和硫酸盐通量之 间的相关系数分别为 -0.50 和 0.57 , 表明有机碳含量 对 SMI 深度和硫酸盐通量具有一定的影响作用; 在 SMI 附近发生了强烈的甲烷厌氧氧化反应, SMI 深度 与硫酸盐 (或甲烷) 通量之间的相关系数为 -0.80 , 表 明 SMI 深度是由上涌的甲烷通量决定的, 甲烷通量 的大小控制了 AMO 的速率以及 SMI 的深浅和硫酸 盐通量; BSR 基本上分布于 $\mathrm{SMI}$ 深度 $<50 \mathrm{mbsf}$ 和硫酸 盐通量 $>3.5 \mathrm{mmol} \mathrm{m}^{-2} \mathrm{a}^{-1}$ 的地区, 这些区域主要位于 白云凹陷和南部隆起, 采获水合物实物样品的 SH2B, SH3B 和 SH7B 钻孔就位于白云凹陷中. 结合地球化 学和地球物理方法进行综合分析认为: 白云凹陷和 南部隆起是神狐海域天然气水合物发育的有利区. 而开展研究区的甲烷厌氧氧化速率和硫酸盐还原速 率的计算和测定, 深入探讨生物地球化学作用及其 与天然气水合物成藏之间的关系将是以后研究的主 要方向之一. 
海底浅表层沉积物样品的采集和现场测试分析得到广州海洋地质调查局“海洋四号”船各调查航次中全体船 员和调查人员的帮助，天然气水合物钻探由中国地质调查局组织、荷兰辉固公司“Bavenit”号钻探船实施，室 内数据的测试分析由广州海洋地质调查局实验测试所和南京大学内生金属矿床成矿机制研究国家重点实验 室完成, 两位审稿专家提出建设性的意见, 在此一并表示衰心的感谢.

\section{参考文献}

1 Berner R A. Early Diagenesis: A Theoretical Approach. Princeton NJ: Princeton University Press, 1980. 1-241

2 Westrich J T, Berner R A. The role of sedimentary organic matter in bacterial sulfate reduction: The G model tested. Limnol Oceanogr, 1984, 2: 236-249

3 Canfield D E. Sulfate reduction in deep-sea sediments. Am J Sci, 1991, 2: 177-188

4 Reeburgh W S. Methane consumption in Cariaco Trench waters and sediments. Earth Planet Sci Lett, 1976, 28: 337-344

5 Borowski W S, Paull C K, Ussler W III. Marine pore-water sulfate profiles indicate in situ methane flux from underlying gas hydrate. Geology, 1996, 7: 655-658

6 Borowski W S, Paull C K, Ussler W III. Global and local variations of interstitial sulfate gradients in deep-water, continental margin sediments: Sensitivity to underlying methane and gas hydrates. Mar Geol, 1999, 159: 131-154

7 Borowski W S, Hoehler T M, Alperin M J, et al. Significance of anaerobic methane oxidation in methane-rich sediments overlying the Blake Ridge gas hydrates. In: Paull C K, Matsumoto R, Wallace P J, et al. Proceedings of the Ocean Drilling Program, Scientific Results, Vol. 164 [CD-ROM]. College Station, Texas: Texas A \& M University (Ocean Drilling Program), 2000. 87-99

8 Dickens G R. Sulfate profiles and barium fronts in sediment on the Blake Ridge: Present and past methane fluxes through a large gas hydrate reservoir. Geochim Cosmochim Acta, 2001, 4: 529-543

9 Borowski W S. Data report: Dissolved sulfide concentration and sulfur isotopic composition of sulfide and sulfate in pore waters, ODP Leg 204, Hydrate Ridge and vicinity, Cascadia Margin, offshore Oregon. In: Tréhu A M, Bohrmann G, Torres M E, et al. Proceedings of the Ocean Drilling Program, Scientific Results Vol. 204 [CD-ROM]. College Station, Texas: Texas A \& M University (Ocean Drilling Program), 2006. 1-13

10 Claypool G E, Kaplan I R. The origin and distribution of methane in sediments. In: Kaplan I R, ed Natural Gases in Marine Sediments. New York: Plenum Press, 1974. 99-139

11 Paull C K, Matsumoto R, Wallace P J, et al. Proceedings of the Ocean Drilling Program, Initial Reports. Vol. 164 [CD-ROM]. College Station, Texas: Texas A \& M University (Ocean Drilling Program), 1996. 1-623

12 Shipboard Scientific Party, Site 1244. In: Tréhu A M, Bohrmann G, Rack F R, et al. Proceedings of the Ocean Drilling Program, Initial Reports, Volume 204 [CD-ROM]. Ocean Drilling Program, Texas A\&M University, College Station, USA. 2003. 1-132

13 Expedition 311 Scientists. Site U1328. In: Riedel M, Collett T S, Malone M J, and the Expedition 311 Scientists. Proc. IODP, 311: Washington, DC (Integrated Ocean Drilling Program Management International, Inc.). doi:10.2204/iodp.proc.311.106. 2006. 1-136

14 杨涛, 蒋少涌, 葛璐, 等. 南海北部神狐海域浅表层沉积物中孔隙水的地球化学特征及其对天然气水合物的指示意义. 科学通报, 2009, 20: 3231-3240

15 Feng D, Chen D F, Peckmann J. Rare earth elements in seep carbonates as tracers of variable redox conditions of ancient hydrocarbon seeps. Terr Nova, 2009, 21: 49-56

16 Feng D, Chen D F, Roberts H H. Petrographic and geochemical characterization of seep carbonate from Bush Hill (GC185) gas vent and hydrate site of the Gulf of Mexico. Mar Pet Geol, 2009, 26: 1190-1198

17 Feng D, Chen D F, Peckmann J, et al. Authigenic carbonates from methane seeps of the northern Congo Fan: Microbial formation mechanism. Mar Pet Geol, 2010, 27: 748-756

18 Chen D F, Cathles L M. A kinetic model for the pattern and amounts of hydrate precipitated from a gas steam: Application to the Bush Hill vent site, Green Canyon Block 185, Gulf of Mexico. J Geophys Res, 2003, 108 (B1), 2058, doi:10.1029/2001JB001597

19 Chen D F, Cathles L M, Roberts H H. The chemical signatures of variable gas venting at hydrate sites. Mar Pet Geol, 2004, 21: 317-326

20 Yang T, Jiang S Y, Yang J H, et al.. Dissolved inorganic carbon (DIC) and its carbon isotopic composition in sediment pore waters from the Shenhu area, northern South China Sea. J Oceanogr, 2008, 2: 303-310

21 Yang T, Jiang S Y, Ge L, et al. Geochemical characteristics of pore water in shallow sediments from Shenhu area of South China Sea and their significance for gas hydrate occurrence. Chin Sci Bull, 2010, 8: 752-760

22 吴能友, 张海啟, 杨胜雄, 等. 南海神狐海域天然气水合物成藏系统初探. 天然气工业, 2007, 9: 1-6

23 Wu N Y, Zhang H Q, Yang S X, et al. Gas hydrate system of Shenhu Area, northern South China Sea: Geochemical results. J Geol Res Volume 2011. doi:10.1155/2011/370298

24 李家彪, 主编. 中国边缘海形成演化与资源效应. 北京: 地质出版社, 2008. 377-384 
25 王存武, 陈红汉, 陈长民, 等. 珠江口盆地白云深水扇特征及油气成藏主控因素. 地球科学一一中国地质大学学报, 2007, 2: 247-252, 266

26 Shipboard Scientific Party. Site 1146. In: Wang P X, Prell W L, Blum P, et al. Proceedings of the Ocean Drilling Program, Initial Reports Volume 184 [CD-ROM]. College Station, Texas: Texas A \& M University (Ocean Drilling Program ), 2000: 1-101

27 吴能友, 杨胜雄, 王宏斌, 等. 南海北部陆坡神狐海域天然气水合物成藏的流体运移体系. 地球物理学报, 2009, 6: 1641-1650

28 王家豪, 庞雄, 王存武, 等. 珠江口盆地白云凹陷中央底辟带的发现及识别. 地球科学一一中国地质大学学报, 2006, 2: 209-213

29 龚跃华, 杨胜雄, 王宏斌, 等. 南海北部神狐海域天然气水合物成藏特征. 现代地质, 2009, 2: 210-216

30 匡增桂, 郭依群. 南海北部神狐海域新近系以来沉积相及水合物成藏模式. 地球科学一一国地质大学学报, 2011, 5: 914-920

31 Zhang H Q, Yang S X, Wu N Y, et al. Successful and surprising results for China's first gas hydrate drilling expedition. Fire in the Ice: Methane Hydrate Newsletter, National Energy Technology Laboratory, U.S. Department of Energy, 2007, Fall, 6-9

32 程思海, 陆红锋. 海洋沉积物孔隙水的制备方法. 岩矿测试, 2005, 2: 102-104

33 杨涛, 蒋少涌, 赖鸣远, 等. 连续流同位素质谱测定水中溶解无机碳含量和碳同位素组成的方法研究. 地球化学, 2006, 6: 675-680

34 Iversen N, J $\varphi$ rgensen B B. Diffusion coefficients of sulfate and methane in marine sediments: Influence of porosity. Geochim Cosmochim Acta, 1993, 57: 571-578

35 Coffin R, Hamdan L, Plummer R, et al. Analysis of methane and sulfate flux in methane-charged sediments from the Mississippi Canyon, Gulf of Mexico. Mar Pet Geol, 2008, 25: 977-987

36 Hensen C, Zabel M, Pfiefer K, et al. Control of sulfate porewater profiles by sedimentary events and the significance of anaerobic oxidation of methane for the burial of sulfur in marine sediments. Geochim Cosmochim Acta, 2003, 67: 2631-2647

37 NiewÖhner C, Hensen C, Kasten S, et al. Deep sulfate reduction completely mediated by anaerobic methane oxidation in sediments of the upwelling area off Namibia. Geochim Cosmochim Acta, 1998, 62: 455-464

38 Treude T, Niggemann J, Kallmeyer J, et al. Anaerobic oxidation of methane and sulfate reduction along the Chilean continental margin. Geochim Cosmochim Acta, 2005, 69: 2767-2779

39 Coffin R, Pohlman J, Gardner J, et al. Methane hydrate exploration on the Mid Chilean coast: A geochemical and geophysical survey. J Pet Sci Eng, 2006, 56: 32-41

40 Wu D D, Wu N Y, Yang R. Relationship of sulfate-methane interface (SMI), methane flux and the underlying gas hydrate in the Dongsha Area, northern South China Sea. Proceedings of the 7th International Conference on Gas Hydrates (ICGH 2011), 2011

41 Shipboard Scientific Party. Site 1144. In: Wang P X, Prell W L, Blum P, et al. Proceedings of the Ocean Drilling Program, Initial Reports, Volume 184[CD-ROM]. College Station, Texas: Texas A \& M University (Ocean Drilling Program ), 2000. 1-97

42 Berner R A. Sulfate reduction and the rate of deposition of marine sediments. Earth Planet Sci Lett, 1978, 37: 492-498

43 Waseda A. Organic carbon content, bacterial methanogenesis, and accumulation processes of gas hydrates in marine sediments. Geochem J, 1998, 3: 143-157

44 Feng D, Roberts H H. Geochemical characteristics of the barite deposits at cold seeps from the northern Gulf of Mexico continental slope. Earth Planet Sci Lett, 2011, 309: 89-99

45 Haese R R, Meile C, Van Cappellen P, et al. Carbon geochemistry of cold seeps: Methane fluxes and transformation in sediments from Kazan mud volcano, eastern Mediterranean Sea. Earth Planet Sci Lett, 2003, 212: 361-375

46 Gieskes J, Mahn C, Day S, et al. A study of the chemistry of pore fluids and authigenic carbonates in methane seep environments: Kodiak Trench, Hydrate Ridge, Monterey Bay, and Eel River Basin. Chem Geol, 2005, 220: 329-345

47 Kastner M, Claypool G, Robertson G. Geochemical constraints on the origin of the pore fluids and gas hydrate distribution at Atwater Valley and Keathley Canyon, northern Gulf of Mexico. Mar Pet Geol, 2008, 25: 860-872

48 Chen Y F, Ussler III W, Haflidason H, et al. Sources of methane inferred from pore-water $\delta^{13} \mathrm{C}$ of dissolved inorganic carbon in Pockmark G11, offshore Mid-Norway, Chem Geol, 2010, 275: 127-138

49 吴庐山, 杨胜雄, 梁金强, 等. 南海北部神狐海域沉积物中烃类气体的地球化学特征. 海洋地质前沿, 2011, 6: 1-10

50 Markl R G, Bryan G M, Ewing J I. Structure of the Blake-Bahama outer ridge. J Geophys Res, 1970, 75: 4539-4555

51 Hyndman R D, Spence G D. A seismic study of methane hydrate marine bottom simulating reflectors. J Geophys Res, 1992, 97: 6683-6698

52 Yuan T, Hyndman R D, Spence G D, et al. Seismic velocity increase and deep-sea hydrate concentration above a bottom simulating reflector on the northern Cascadian slope. J Geophys Res, 1996, 101: 13655-13671

53 宋海斌, 张岭, 江为为, 等. 海洋天然气水合物的地球物理研究(III): 似海底反射. 地球物理学进展, 2003, 2: 182-187

54 Reed D L, Lundberg N, Liu C S, et al. Structural relations along the margin of the offshore Taiwan accretionary: Implications for accretion and crustal kinematics. Acta Geol Taiwan, 1992, 30: 105-122

55 姚伯初. 南海北部陆缘天然气水合物初探. 海洋地质与第四纪地质, 1998, 4: 11-18

56 张毅, 何丽娟, 徐行, 等. 南海北部神狐海域甲烷水合物 BHSZ 与 BSR 的比较研究. 地球物理学进展, 2009, 1: 183-194

57 方银霞, 初风友. 硫酸盐-甲烷界面与甲烷通量及下伏天然气水合物赋存的关系. 海洋学研究, 2007, 1: 1-9

58 Fang Y X, Chu F Y. The relationship of sulfate-methane interface, the methane flux and the underlying gas hydrate. Mar Sci Bull, 2008, 1: $28-37$ 